\title{
Two Stages Thermal and Catalytic Cracking of Polyethylene Terephthalate to Fuel Production
}

\author{
Shams N. Almutalabi, Mohammed Alzuhairi*, Fadhil A. Hashim \\ Department of Materials Engineering, University of Technology, Baghdad 10069, Iraq
}

Corresponding Author Email: mohammed.a.alzuhairi@uotechnology.edu.iq

https://doi.org/10.18280/ijdne.160615

Received: 14 August 2021

Accepted: 24 September 2021

\section{Keywords:}

PET plastic, calcium hydroxide, pyrolysis, fuel, GC/MS

\begin{abstract}
PET (polyethylene terephthalate) is made up of polymerized repeating units of the ethylene terephthalate monomer $\left(\mathrm{C}_{10} \mathrm{H}_{8} \mathrm{O}_{4}\right)$. PET is a recyclable plastic with the number 1 as its identification code. PET, which has a molecular weight of $192 \mathrm{gm} / \mathrm{mole}$ and contains 62.5 percent carbon, 33.3 percent oxygen, and 4.2 percent hydrogen, is utilized as synthetic fiber, polyester, plastic packaging, and soft drink containers all over the world. The main purpose of this study is to convert PET waste into liquid hydrocarbon fuel. Because PET use has risen significantly over the world, and the bulk of garbage is thrown into the soil rather than recycled, posing an environmental risk. During the heat breakdown phase, PET decomposes. It creates very strong and solid non-biodegradable terephthalic acid and benzoic acid complexes. To obtain liquid hydrocarbon fuel from PET, at $250-300^{\circ} \mathrm{C}$, calcium hydroxide $\mathrm{Ca}(\mathrm{OH})_{2}$ is used as a catalyst in this study.
\end{abstract}

\section{INTRODUCTION}

PET, or polyethylene terephthalate, is largely utilized to manufacture the packaging industry, and soft drinks bottles.

PET is a thermoplastic polymer with long branches that can be repurposed and bring economic advantages if recycled properly, is a part of the polyester's groups [1].

Waste bottles made of these materials have grown significantly in popularity. Bottles have a noteworthy position in the recycling sector due to their great resilience to breakage, gas diffusion, and temperature, as well as their lower price and weight in comparison to certain materials like metals, and glass [2].

PET is a significant material because it is a key component of plastics used in various applications. By 2021, PET usage will approach 20 million tons. PET waste is generated in large quantities as a result of its widespread use. However, PET's properties, such as its minimal natural deterioration and heat stability [3]. Have produced major problems in the environment and with human health [4].

These discarded plastic materials may persist for a long period in landfills and the environment. As a result, when these plastics reach the environment, they cause a slew of issues. They have the potential to clog sewers, offer a breeding habitat for mosquitoes and disease-carrying pests, leak harmful compounds, and enter the human food chain [5].

Polymers are low-cost, lightweight, and hard materials that can be easily shaped into a variety of products that can be used in a variety of applications, but they are low-cost lightweight and hard materials that can be easily shaped into a variety of products that can be used in a variety of applications. As a result, in the last 60 years, plastics production has grown substantially [6]. Chemical recycling is the most effective method from an environmental and sustainability standpoint because it produces new raw materials that can then be reused to manufacture chemicals and petroleum products. Then, it's really a possible way to solve this bulk waste material issue [7].

Different reactions, such as methanolysis and glycolysis, can be used to recycle PET chemically. Glycolysis methods use a variety of glycols, including ethylene glycol, diethylene glycol, and others [8].

PET plastics are used on a daily basis all around the world and then dumped in landfills. Because PET does not biodegrade in landfills, its existence in the landfill creates several of the environmental and economic issues. PET waste undergoes photo degradation, resulting in minuscule particles that penetrate the food chain and pose a health risk to residents. PET becomes a very hard rigid complex sublimate material during the incineration process, which causes serious environmental problems. In addition, incineration promotes the release of toxic greenhouse gases [9].
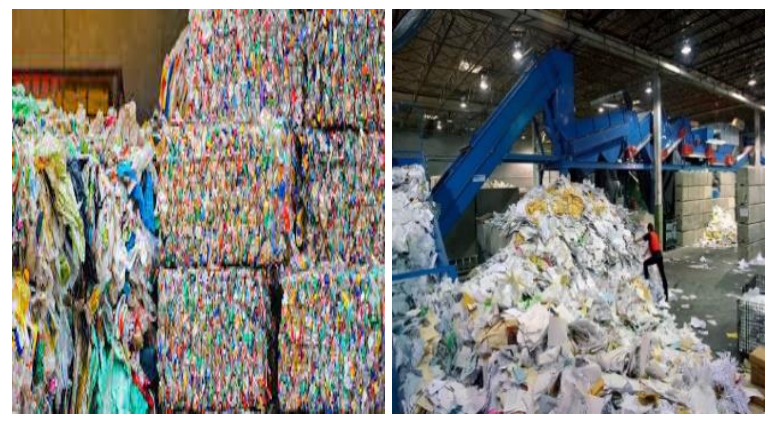

Figure 1. Recycling of PET

Figure 1 illustrates the concept of recycling, Extensive use of (PET) results in unused materials, which can be difficult to manage [10].

With a Si/Al ratio of 3.1, Zeolite Y was prepared using Iraqi kaolin in 2016 and evaluated as a catalyst in the liquid-phase transesterification of oleic acid. The findings show that zeolite 
$\mathrm{Y}$ with a low $\mathrm{Si} / \mathrm{Al}$ ratio is a suitable catalyst for fuel production and esterification, which contradicts the widely held belief that zeolites are unsuitable for such applications [11].

In 2017, monomers and oligomers of bis (2-hydroxyethyl) terephthalate (BHET) were synthesized using a glass condenser for chemical recycling at $190^{\circ} \mathrm{C}$ from nano-zinc oxide with varying particle sizes and weight ratios. Different types of monomers and dimers are formed [12].

While In 2018, Additional heater in the bubble column reactor highlighted the chemical depolymerization of PET using the shutdown system of ethylene glycol nitrogen glycolysis process, a PET catalyst, and nitrogen in a threestage bubble column using a Nano catalyst, $\mathrm{SiO}_{2}$ with different weight ratio based on the weight of PET and nitrogen preheated to $100^{\circ} \mathrm{C}$. The final product of PET depolymerization was thoroughly characterized using FTIR, AFM, and CHN tests [13]. In addition, the catalyzed pyrolysis of polystyrene and PET was investigated to determine the influence of PET on the pyrolysis of PS. The primary reaction was carried out in a batch tubular reactor to test the effect of temperature and residence time. Furthermore, the physical properties of the produced liquid, such as density, viscosity, and caloric value, were investigated, and the results were 0.9 $\mathrm{g} / \mathrm{cm}^{3}, 2-3 \mathrm{Cp}$, and $40-45 \mathrm{MJ} / \mathrm{kg}$, respectively [14]. PET microorganisms isolated from soil samples were also tested for biodegradability. Thirty-eight bacterial isolates were isolated from ten soil and material waste samples collected at four different waste disposal locations in Baghdad city at different times. The results showed that the saffron sample produced the most isolates, while the other samples produced fewer. During the screening process, the ability to grow in liquid MSM containing PET powder, cut and modify the color of the emulsified PET medium, and create the liquid region on PETMSM agar were all taken into account [15]. Pyrolysis, which converts plastic waste into valuable products in the presence of heat, has been identified as the most appropriate chemical recycling technique [16]. It also entails the development of blends containing various combinations of depolymerized Polyethylene Terephthalate (DPET), an Unsaturated Polyester Resin, and Ravemul VV/55 in order to reduce pollution by recovering plastic waste. The tests show that the presence of unsaturated polyester resin improves mechanical properties and increases cohesiveness in 2021 [17].

\section{POLYETHYLENE TEREPHTHALATE (PET)}

Polyethylene Terephthalate is typically referred to as (Polyester) in the packaging industry and (Polyester) in the material industry. High-strength, transparent, and propertysafe semi-crystalline thermoplastic polyester. Because of its excellent chemical and physical properties, it is an indispensable material with various applications. The disposal of polyethylene terephthalate waste, on the other hand, has produced severe economic and environmental concerns as a result of their increasing use and non-biodegradability. As a result, waste management of PET has become a significant social issue. Recycling is still the most sustainable treatment option for polyethylene waste, according to a study of community environmental awareness. Among the various methods for recycling PET, major or "in the plant," minor or mechanical, tertiary or chemical, quaternary including energy recovery, chemical recycling is the only source of long-term improvement. Glycolysis, ammonolysis, methanolysis, and aminolysis are examples of chemical recycling techniques. Chemical recycling in a wide range of applications. The main goal of PET research is to increase monomer production while reducing reaction time and executing reactions under controlled circumstances. Researchers' continued efforts have resulted in major advances in chemical recycling methods; the recycling of PET is depicted in the Figure 1 [18].

\section{IMPORTANCE OF POLYETHYLENE TEREPHTHALATE IN MANUFACTURING}

PET has been used in the production of textile fibers since the mid-to-late 1940s. Nathaniel Wyeth developed the PET bottle in 1973, and it became common in the 1980s for the production of beverage bottles. PET was consumed in the production of almost 700 million pounds in 1987. In the year 2000 , global polyester production was estimated to be between 25 and 30 million tons. But in 2012, this rate grew to 55 million tons, with PET accounting for the majority of the total. Because of the high demand for textile applications, polyester usage has increased rapidly in the fiber and resin molding industries, as well as in food markets and packaging to replace glass bottles. The global market today controls two polyethylene terephthalates: bottle-grade PET and fiberglass PE. In addition to colorings, PET differs in the kind and number of common monomers, catalysts, and stabilizers. Polyethylene terephthalates for textile fibers have a molecular weight of $15,000-20,000 \mathrm{gm} / \mathrm{mol}$, indicating a natural viscosity of 0.55 to $0.67 \mathrm{gm}$. PET fiber grades for practical threads, such as tire cords, have high molecular weights and viscosity. The amorphous condition of bottle grade PE polyethylene terephthalates (Glass - Clear). The mean molecular weight varies between 24,000 and $36,000 \mathrm{gm} / \mathrm{mol}$, indicating high viscosity. The Other grades of PET are used to make packaging films, as well as audio and videotapes and videos [19].

\section{IDENTIFICATION CODE OF PLASTIC}

All around the world, five different types of plastic polymers are utilized for packaging purposes, each with its own features. Plastic identification code (PIC), often known as an electronic abbreviation or a number, can be used to identify each type of plastic polymer. For example, the "4" low-density polyethylene identifying numbers or the symbols (LDPE). PIC appears to be chasing the third sign inside the recycling arrow. The symbol is used to indicate whether or not the item may be recycled into other plastic items. The Plastic Industry Association established PIC to give a standardized system for identifying different polymer types and to assist various recycling groups that separate plastics for recycling. Customers can identify different types of plastics by looking for codes on the bottom or sides of plastic products such as chemical packing and food containers. Typically, the PIC is not displayed on packing films, making it more difficult to save and recycle the majority of this type of waste [20].

\section{RECYCLING METHODS OF PLASTIC WASTE}

Mechanical and chemical recycling is the most efficient 
method for recycling Polyethylene Terephthalate. Because mechanical recycling of PET contains adhesive contamination, the quality of the recovered PET will decrease. Chemical recycling of PET is even more expensive than mechanical recycling because the former requires the use of chemicals such as catalysts at a specific temperature and under high pressure [21].

- Mechanical recycling, also known as physical recycling, reprocesses PET material by melting extrusions of the material after they have been separated from their pollutants. It mostly includes the processes and treatments listed below:

1) Keeping PET separate from other plastics.

2) Cleaning and drying the dust and other pollutants.

3) Due to reuse, grind the PET particles to decrease their size.

4) Extrusion by heat.

5) The PET materials are shaped and ground.

6) Physical recycling is easier to implement and needs less effort in general than chemical recycling [22].

- Chemical recycling is a form of recycling that differs from physical recycling. Before re-use, this process chemically polymerizes or degrades PET waste. Hydrogenation, glycolysis, aminolysis, methanolysis, and hydrolysis just are a few of the chemical recycling mechanisms that can be employed [23].

Several types of amines, such as polyamines, ethanolamine, allylamine, and tri-ethanol amine, can be used to depolymerize PET waste material. PET compounds such as plasticizers and hard polyurethane foams are made using the aminolysis response [24].

\section{CHEMICAL RECYCLING OF POLYETHYLENE TEREPHTHALATE (PET)}

At the time, PET was the most commonly used plastic on the planet. Chemical recycling is believed to be the most sustainable form of natural recycling because of its wide application in a variety of applications, allowing the healing of scarce materials and other relevant chemicals in processing with long-term waste dumping difficulties [25]. Decomposition is easy and stable between them, requiring only low to moderate process conditions and capital investment. See Table 1 [26].

Table 1. Economic considerations and process for polyethylene terephthalate monomer recovery methods

\begin{tabular}{|c|c|c|c|}
\hline $\begin{array}{l}\text { Recycling } \\
\text { Process }\end{array}$ & $\begin{array}{l}\text { Qualitative } \\
\text { Plant Cost }\end{array}$ & $\begin{array}{c}\text { Economically } \\
\text { Competitive } \\
\text { Scale } \\
\end{array}$ & $\begin{array}{c}\text { Safety } \\
\text { Condition }\end{array}$ \\
\hline Hydrc & High & Large Plants & $\mathrm{Hi}$ \\
\hline Methanolysis & High & Large Plants & High \\
\hline Glycolysis & Medium-Low & Small Plants & Medium \\
\hline
\end{tabular}

The condensation monomer of Polyethylene Terephthalate bis ( 2 hydroxyethyl terephthalate) or BHET is one of the products of decomposition. The oligomers have a low molecular weight, so they are filtered to being used in production of PET or altered to another chemical. Modern efforts to develop improved catalysts have indeed been guided by critical concerns in product purification and process efficiency [26].

PET is created by mixing multiple condensations with ethylene glycol (EG) with terephthalic acid in a stage-growth process (TPA). Polyethylene terephthalate is installed using two different reactions at the start. The first is the esterification reaction, which involves reacting EG with TPA to form bis hydroxyethyl terephthalate (BHET) as a precursor polymer. And the other was the transesterification reaction, which includes the reaction of dimethyl terephthalate (DMT); Because of the ease at which DMT can be purified by distillation, Transesterification was a highly desired method in the early years of PET production. Because of their great purity, most PET manufacturing techniques have changed from DMT to TPA as the primary component.

One technique to support the circular economy is to include diverse waste materials and side fractions into wood-plastic composites (WPC) [27].

Using the Box-Wilson way of experimental design, the effects of experimental variables on the properties of an improved asphalt mix were investigated, and useful relationships were discovered [28].

\section{MECHANICAL RECYCLING OF POLYETHYLENE TEREPHTHALATE (PET)}

Thermoplastic PET can be recycled mechanically, but thermoset PET cannot be recycled since it cannot be remolded with heat. Because of the waste stream's complexity, the recycling process of contaminated PET wastes is difficult.

The variability of PET waste and the loss of product qualities each time it is recycled are the two most significant challenges for mechanical recycling. Small amounts of another polymer inserted in the PET matrix can dramatically alter PET characteristics, preventing it from being used in traditional applications.

Furthermore, like most polymers, PET degrades during usage due to a variety of elements such as temperature, UV. Light, oxygen, ozone, and mechanical forces, resulting in recycled PET having different properties and performing worse than virgin PET. Another issue with recycled PET Is that it has an unappealing grey tint due to the presence of PET waste manufactured from the same resin [2].

\section{CHEMISTRY, SYNTHESIS, MANUFACTURE AND CHARACTERISTICS OF (PET)}

Pure terephthalic acid (TPA) is esterified, and ethylene glycol is produced at $240-260^{\circ} \mathrm{C}$ and $300-500 \mathrm{KPa}$, with an excess of ethylene glycol of $\left(100-150^{\circ} \mathrm{C}\right)$ and (1070) bar, derived from crude oil, for the PET industry's intermediates. When heated together, the initial result is a monomer Bis (2Hydroxyethyl) terephthalate (BHET). The intermediate, Bis (2-Hydroxyethyl) Terephthalate, is then polycondensed at a higher temperature $\left(150-270^{\circ} \mathrm{C}\right)$ under vacuum and frequently with a catalyst, like: $\mathrm{Zn}\left(\mathrm{O}_{2} \mathrm{CCH}_{3}\right)_{2}$.

The PET is a viscous molten liquid at this step. Some PET is also made from the transesterified dimethyl ester of terephthalic acid (DMT). It's done at a temperature of 140 $220^{\circ} \mathrm{C}$ and a pressure of $100 \mathrm{KPa}$. [29, 30]. PET's high molecular weight is achieved through a second polymerization stage that takes place in a solid-state at low temperatures. All 
volatile contaminants, such as water and free glycols, as well as acetaldehyde, are thoroughly removed. Superior mechanical properties, including toughness, stiffness, and creep resistance, require a larger molecular weight. As well as enough flexibility to avoid bursting and fracturing under pressure because it's so difficult to purify a polymer once it's been made, the purity of the basic materials is the most critical consideration. Vacuum distillation is used to refine ethylene glycol, while serial crystallization is used to purify of (TPA). Manganese, cobalt, germanium, magnesium, and zinc are examples of catalysts that are used at extremely low concentrations to assure practical economics and promote reactions [29].

\section{EXPERIMENTAL WORK PROCEDURE}

\subsection{Content}

The first stage, the waste (PET) bottles are cleaned and dried before being cut into square chips with a particle size of $(3 \times$ 3) $\mathrm{mm}$. the density and melting point of PET are shown in Table 2. Then (EG), which is employed as a glycolysis solvent. Mixed with magnesium oxide $(\mathrm{MgO})$ which is used as catalysis are shown in Figure 2, this experiment led to produce of Degraded Polyethylene Terephthalate (DPET). The chemicals utilized are all of the high purity and are not purified before use.

Table 2. The PET waste's physical characteristics

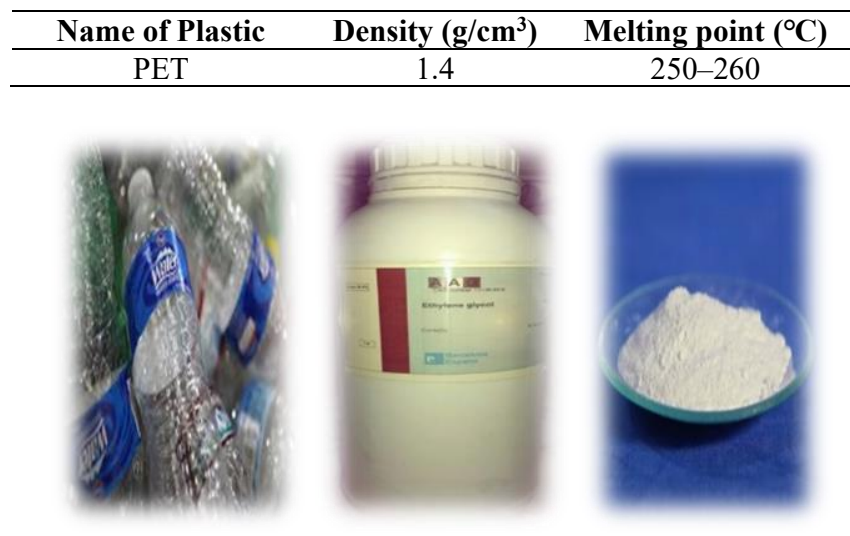

Figure 2. Materials used in this work

\subsection{Catalyst}

In second stage, by pyrolysis process, it is a thermal degradation of materials in an inert atmosphere at high temperatures. It includes changes in chemical structure. At $250-300^{\circ} \mathrm{C}$, the pyrolysis process was used to convert waste PET into liquid fuel without creating any sublimate compounds. This Fuel was created by mixing suitable ratio from the DPET with catalysts such as: $\mathrm{FeOOH}, \mathrm{Fe}_{2} \mathrm{O}_{3}$, $\mathrm{Ni}(\mathrm{OH})_{2}$, and $\mathrm{Ca}(\mathrm{OH})_{2}$. In This research used only calcium hydroxide $\left(\mathrm{Ca}(\mathrm{OH})_{2}\right)$ for experiments.

\subsection{Preparation of the samples}

During the first stage, 100 grams of PET were combined with 116 milliliters of EG., with $0.5 \%$ of Nano $\mathrm{MgO}$ as a catalyst, based on the weight of PET was heated in $190^{\circ} \mathrm{C}$ for
5 hours until it is placed in a resin casing. Through the employment of glass condenser water cooling, and the heat treatment comprises complete condensation in a closed system without material loss. Then, as indicated in Figure 3, the unreacted solution from (EG.) is removed from the prior combination, leaving the final form of Degraded Polyethylene Terephthalate (DPET). With the container was cooled to room temperature, after reaction.

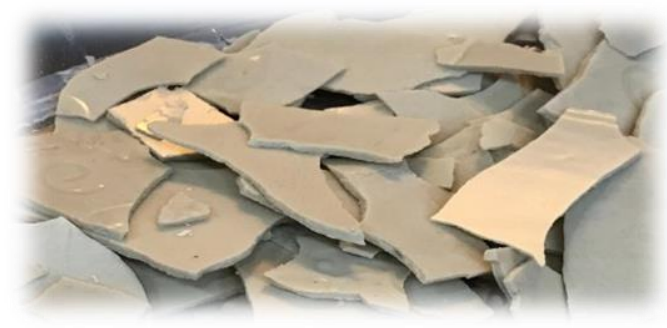

Figure 3. Powder product after filtrations

While, Figure 4 displays a close system of chemical recycling for PET, complete with a U-tube manometer. To measure the pressure above the apparatus of a closed system, to ensure that no vapors or materials are lost from the system.
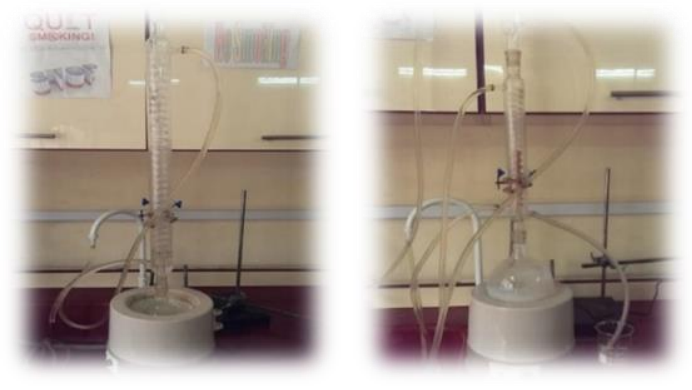

Figure 4. Close system of chemical recycling and after Separation of UN reacted EG. From mixture

About $1000 \mathrm{~mL}$ distilled water was added to the depolymerization product (DPET) with (17) grams. Of DPET to make the purification product from EG. Then, heat and mix, and use the magnetic stirrer hot plate shown in Figure 5, the remaining EG would be dissolved as a result of this. The mixture was vacuum filtered when the product was cooled to room temperature. In the filtrate, white crystalline chips of monomers were formed. They were then separated and dried for 24 hours in room air, as illustrated in Figure 6.

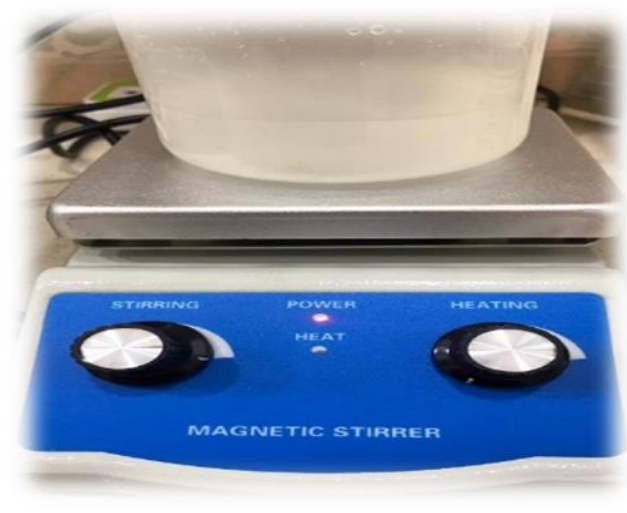

Figure 5. Magnetic stirrer hot plate 


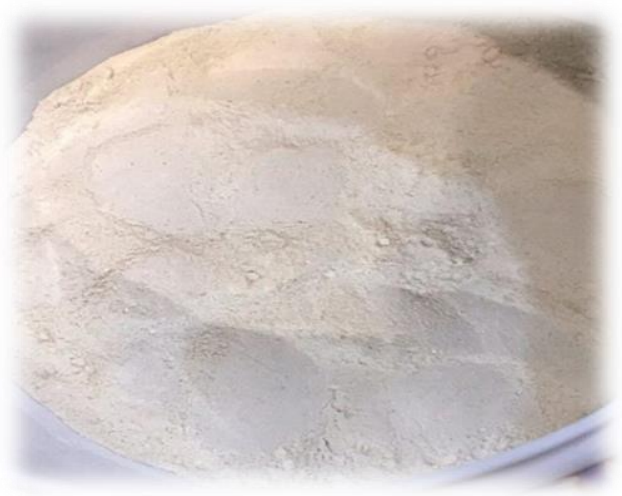

Figure 6. Powder product after filtrations

Then both calcium hydroxide $\mathrm{Ca}(\mathrm{OH})_{2}$ catalyst and DPET powder were mixed with a ratio of $50 \mathrm{gm}$. for each substance, Shown in Figure 7. With a temperature controller (heater), a heating mantle was used to place a boiling flask containing the sample (Figure 8). For rapid melting of DPET, the boiling flask had been heated up to $270^{\circ} \mathrm{C}$, with $90 \%$ heater performance. The condenser pipe began to fill with the vapor within 10 minutes. After 45 minutes, the mixture began to break down and disintegrate to form two phases of liquid fuel and the remaining ethylene glycol and other chemicals shown in Figure 9 with the mixture burning from process remain inside the beaker shown in Figure 10. By Pyrolysis that is a process for converting DPET to fuel that involves the thermal degradation of materials at high temperatures in an inert atmosphere. With the fuel for fire shown in the Figure 11.
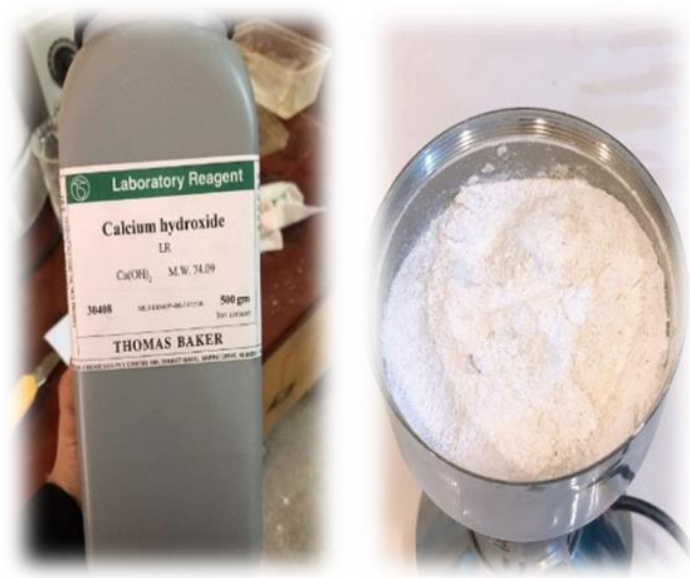

Figure 7. Mixing calcium hydroxide and DPET powder

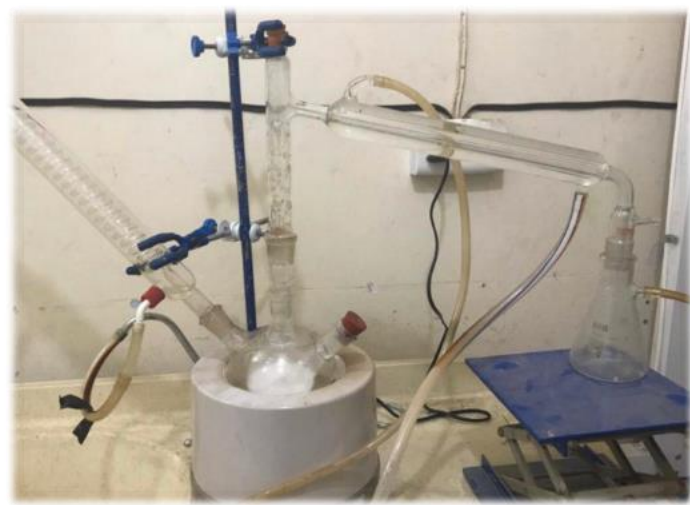

Figure 8. Method of converting DPET to fuel

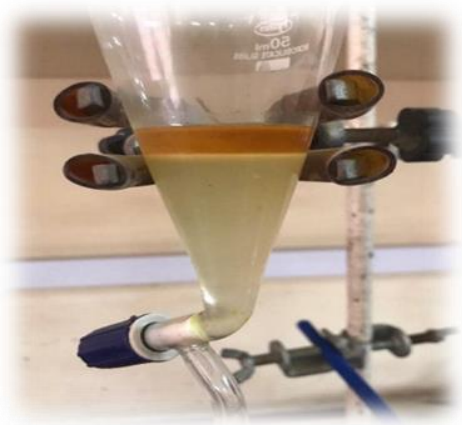

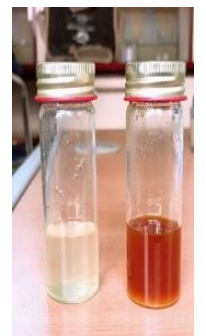

Two phases

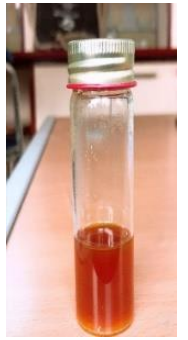

Fuel

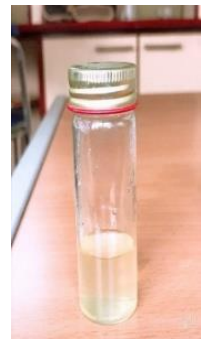

EG. + Other
Figure 9. Two phase's products from pyrolysis process

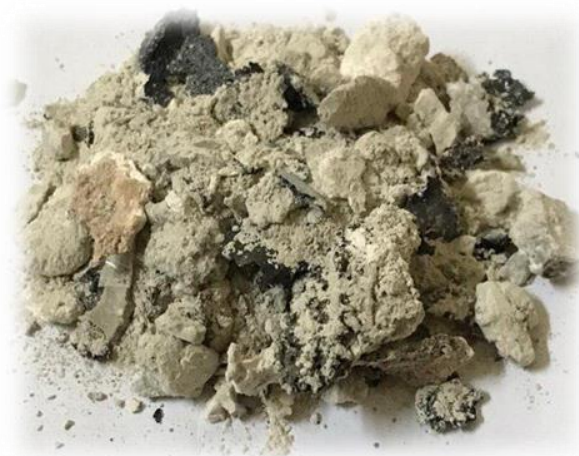

Figure 10. Burnt powder left over from the process

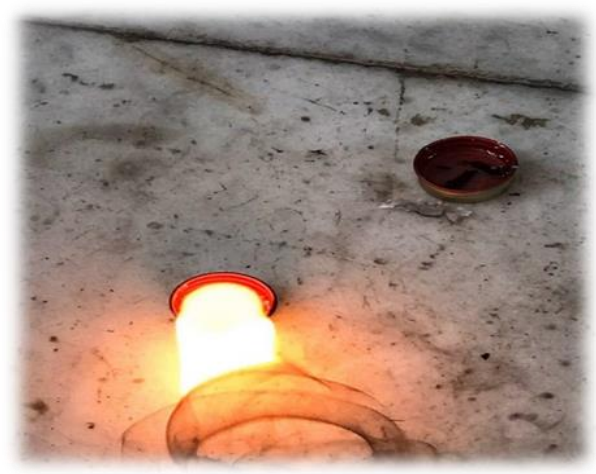

Figure 11. Firing process of fuel

\section{RESULTS AND DISCUSSION}

The results have been focusing on mechanical and chemical bases:

\section{a. Gas Chromatography of -mass spectrometry (GC-MS)}

A new research laboratory type of equipment (GC/MS Agilent to characterize the PET liquid fuel product). The 
sample of fuel was passed through some tests like the chromatography/mass spectrophotometer. The compounds of fuel were identified by using GC/MS. The fuel chromatogram shows a long carbon chain with peak abundances confirming the chemicals. And compounds are shown in the Table 3, according to GC/MS data, fuel has a wide spectrum of hydrocarbon groups, leading in a higher thermal substance.

Table 3. GC mass compounds

\begin{tabular}{|c|c|c|c|}
\hline No. & Area \% & $\begin{array}{c}\text { RT } \\
\text { (Min) }\end{array}$ & Compound Name \\
\hline 1 & 3.89 & 4.75 & $\begin{array}{l}\text { Benzene, } 1,3 \text { dimethyl-2 } \\
\text { Ethylbenzene }\end{array}$ \\
\hline 2 & 2.74 & 5.40 & $\begin{array}{c}\text { Bicyclo [4.2.0] octane-1,3,5 triene- } \\
\text { Styrene }\end{array}$ \\
\hline 3 & 0.74 & 5.72 & No matches found \\
\hline 4 & 0.61 & 6.35 & $\begin{array}{l}\text { 4-Hydroxy-2-oxo-2H-chromene-3- } \\
\text { carbaldehyde }\end{array}$ \\
\hline 5 & 0.86 & 6.55 & No matches found \\
\hline 6 & 1.84 & 7.51 & No matches found \\
\hline 7 & 0.20 & 8.37 & No matches found \\
\hline 8 & 29.32 & 9.13 & Acetophenone \\
\hline 9 & 1.49 & 11.94 & 2 Naphthalene \\
\hline 10 & 1.11 & 14.46 & $\begin{array}{c}\text { Benzene, 1-(1,1-dimethylethyl)-4- } \\
\text { ethyl-Ethanone, } 1 \text { - } \\
\text { (2,4_dimethylphenyl) }\end{array}$ \\
\hline 11 & 16.22 & 15.87 & 3 Biphenyl \\
\hline 12 & 12.45 & 16.86 & $\begin{array}{l}\text { Diphenylmethane } \\
\text { 1,1-Biphenyl,2-methyl- } \\
\text { Diphenylmethane }\end{array}$ \\
\hline 13 & 0.36 & 18.64 & No matches found \\
\hline 14 & 3.38 & 20.58 & 3 Fluorene \\
\hline 15 & 2.28 & 21.39 & 3 Benzophenone \\
\hline 16 & 7.62 & 21.91 & 3 n-Hexadecanoic acid \\
\hline 17 & 0.23 & 24.78 & No matches found \\
\hline 18 & 7.63 & 27.22 & 3 Triphenylmethane \\
\hline 19 & 1.02 & 27.93 & Iron,tricarbonyl \\
\hline 20 & 1.19 & 29.47 & Triadimefon \\
\hline 21 & 2.75 & 29.72 & $\begin{array}{l}\text { 9H-Fluorene,9-phenyl-9H- } \\
\text { Fluorene,9-phenyl- } \\
\text { Benz(a)anthracene,7-methyl- }\end{array}$ \\
\hline 22 & 0.85 & 30.03 & $\begin{array}{l}\text { Urea, 5-Amino-6-nitroso- } \\
\text { 2,4(1H,3H)-pyrimidinedione } \\
\text { Pterin-6-carboxylic acid }\end{array}$ \\
\hline 23 & 1.04 & 30.28 & No matches found \\
\hline 24 & $\begin{array}{c}0.19 \\
\text { Total } \\
=100 \%\end{array}$ & 30.89 & No matches found \\
\hline
\end{tabular}

\section{b. Relationship between temperature and time when producing a fuel material}

Through the multiple experiments, it was found that the higher the temperature, the less time required for the disintegration of materials, and this leads to an acceleration of the decomposition process. This is evidence of the efficiency of the DPET material used in the cracking process and the reduction of the time required for the total process, as shown in Figure 12.

\section{c. Relationship between the ratios of $\mathrm{Ca}(\mathrm{OH})_{2}$ / DPET powder when producing a fuel material}

When conducting experiments, it was found when increasing the amount of ratio $\mathrm{Ca}(\mathrm{OH})_{2} /$ DPET powder, leads to a decrease in fuel production shown in Figure 13(a). But when the amount ratio is lower, that leads to an increase in fuel production of more than $10 \mathrm{ml}$ because increase over cracking shown in Figure 13(b).

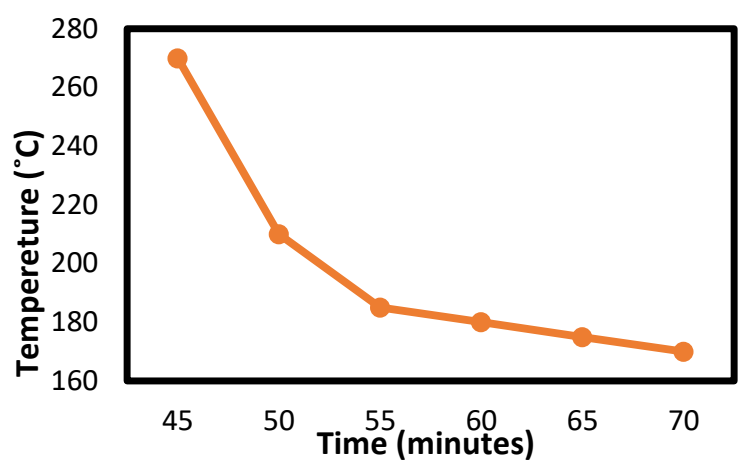

Figure 12. Relationship between temperature and time
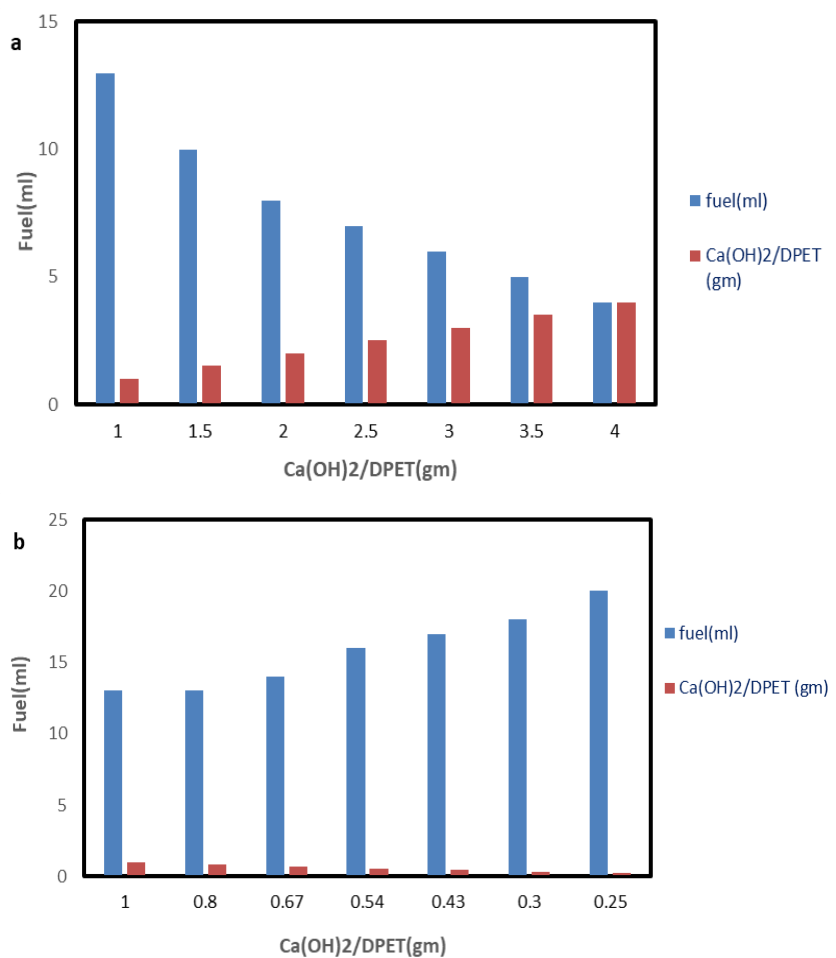

Figure 13. Amount ratio of $\mathrm{Ca}(\mathrm{OH})_{2} /$ DPET powder to fuel

\section{CONCLUSIONS AND RECOMMENDATIONS}

The results of this study will be useful and beneficial in the future for polyethylene terephthalate applications by recycling process, as a result, the following conclusion might be made:

1. The use of the catalyst ratios succeeded in cracking DPET and getting over cracking with large quantities of catalyst, with a higher yield and productivity for small amounts.

2. The use of DPET in various materials applications reduced the cost due to the low cost of the DPET production in the fuels production.

3. The use of PET in sustainable has given the radical solution to plastic waste problems in the world and not just a recycling process.

4. The fuel, produced from plastic waste, has specifications that are close to the specifications of the local fuel produced and therefore it can be used in diesel engines and other applications. 
5. A catalytic converter is used in the thermal degradation process to transform waste DPET plastic into hydrocarbon fuel. According to the GC/MS results, the DPET contains a lot of volatile hydrocarbon compounds.

6. The use of other catalysts like $\mathrm{FeOOH}, \mathrm{Fe}_{2} \mathrm{O}_{3}$, and $\mathrm{Ni}(\mathrm{OH})_{2}$ and hybrids in the cracking of plastic waste and produce liquid fuel.

7. Using other wastes such as HDPE, LDPE, PVC, PP, and PS to produce fuels.

\section{REFERENCES}

[1] Welle, F. (2011). Twenty years of PET bottle to bottle recycling-An overview. Resources, Conservation and Recycling, 55(11): 865-875. https://doi.org/10.1016/j.resconrec.2011.04.009

[2] Bartolome, L., Imran, M., Cho, B.G., Al-Masry, W.A., Kim, D.H. (2012). Recent developments in the chemical recycling of PET. Material Recycling-Trends and Perspectives. https://doi.org/10.5772/33800

[3] Ghanbari, A., Heuzey, M.C., Carreau, P.J., Ton-That, M.T. (2013). A novel approach to control thermal degradation of PET/organoclay nanocomposites and improve clay exfoliation. Polymer, 54(4): 1361-1369. https://doi.org/10.1016/j.polymer.2012.12.066

[4] Hurley, R., Woodward, J., Rothwell, J.J. (2018). Microplastic contamination of river beds significantly reduced by catchment-wide flooding. Nature Geoscience, 11(4): 251-257. https://doi.org/10.1038/s41561-0180080-1

[5] UNEP, U. (2018). Single-use plastics: A roadmap for sustainability, United Nations Environment Programme. http://hdl.handle.net/20.500.11822/25496.

[6] Hopewell, J., Dvorak, R., Kosior, E. (2009). Plastics recycling: Challenges and opportunities. Philosophical Transactions of the Royal Society B: Biological Sciences, 364(1526):

$2115-2126$ https://doi.org/10.1098/rstb.2008.0311

[7] Lithner, D. (2011). Environmental and health hazards of chemicals in plastic polymers and products. http://hdl.handle.net/2077/24978.

[8] Sinha, V., Patel, M.R., Patel, J.V. (2010). PET waste management by chemical recycling: A review. Journal of Polymers and the Environment, 18(1): 8-25. https://doi.org/10.1007/s10924-008-0106-7

[9] Miskolczi, N., Bartha, L., Deak, G., Jover, B. (2004). Thermal degradation of municipal plastic waste for production of fuel-like hydrocarbons. Polymer Degradation and Stability, 86(2): 357-366. https://doi.org/10.1016/j.polymdegradstab.2004.04.025

[10] Sangalang, A., Seok, S. (2016). Practical design of green catalysts for PET recycling and energy conversion. In Advanced Catalytic Materials-Photocatalysis and Other Current Trends. IntechOpen. https://doi.org/10.5772/62041

[11] Doyle, A.M., Albayati, T.M., Abbas, A.S., Alismaeel, Z.T. (2016). Biodiesel production by esterification of oleic acid over zeolite Y prepared from kaolin. Renewable Energy, $\quad$ 97: 19-23. https://doi.org/10.1016/j.renene.2016.05.067

[12] Alzuhairi, M.A.H., Khalil, B.I., Hadi, R.S. (2017). Nano $\mathrm{ZnO}$ catalyst for chemical recycling of polyethylene terephthalate (PET). Engineering and Technology
Journal, 35(8 Part A): 831-837.

[13] Alzuhairi, M. (2018). Bubble column and CFD simulation for chemical recycling of polyethylene terephthalate. In AIP Conference Proceedings, 1968(1): 030041. https://doi.org/10.1063/1.5039228

[14] Almukhtar, R.S., Abduallah, S.I.H. (2018). Characterization of liquid produced from catalytic pyrolysis of mixed polystyrene and polyethylene terephthalate plastic. Engineering and Technology Journal, 36(1): 27-32. http://dx.doi.org/10.30684/etj.36.1A.4

[15] Hussein, A.A., Alzuhairi, M., Aljanabi, N.H. (2018). Degradation and depolymerization of plastic waste by local bacterial isolates and bubble column reactor. In AIP Conference Proceedings, 1968(1): 030081. https://doi.org/10.1063/1.5039268

[16] Hussein, Z.A., Shakor, Z.M., Alzuhairi, M., AlSheikh, F. (2021). Thermal and catalytic cracking of plastic waste: A review. International Journal of Environmental Analytical https://doi.org/10.1080/03067319.2021.1946527

[17] Mohammed, H., Alzuhairi, M., Ibrahim, S.I., Hussein, S.S. (2021). Ternary waste plastic blends for binding and adhesion. International Journal of Environmental Studies, 1-11. https://doi.org/10.1080/00207233.2021.2006919

[18] Thiounn, T., Smith, R.C. (2020). Advances and approaches for chemical recycling of plastic waste. Journal of Polymer Science, 58(10): 1347-1364. https://doi.org/10.1002/pol.20190261

[19] Al-Sabagh, A.M., Yehia, F.Z., Eshaq, G., Rabie, A.M., ElMetwally, A.E. (2016). Greener routes for recycling of polyethylene terephthalate. Egyptian Journal of Petroleum, 25(1): 53-64. https://doi.org/10.1016/j.ejpe.2015.03.001

[20] Geyer, R., Jambeck, J.R., Law, K.L. (2017). Production, use, and fate of all plastics ever made. Science Advances, 3(7): e1700782. https://doi.org/10.1126/sciadv.1700782

[21] Raheem, A.B., Noor, Z.Z., Hassan, A., Abd Hamid, M.K. Samsudin, S.A., Sabeen, A.H. (2019). Current developments in chemical recycling of post-consumer polyethylene terephthalate wastes for new materials production: A review. Journal of Cleaner Production, 225:

1052-1064. https://doi.org/10.1016/j.jclepro.2019.04.019

[22] Leng, Z., Padhan, R.K., Sreeram, A. (2018). Production of a sustainable paving material through chemical recycling of waste PET into crumb rubber modified asphalt. Journal of Cleaner Production, 180: 682-688. https://doi.org/10.1016/j.jclepro.2018.01.171

[23] Shukla, S.R., Harad, A.M. (2006). Aminolysis of polyethylene terephthalate waste. Polymer Degradation and Stability, 91(8): 1850-1854. https://doi.org/10.1016/j.polymdegradstab.2005.11.005

[24] Parab, Y.S., Wasekar, P.A., Mhaske, S.T., Shukla, S.R. (2014). Novel synthesis, characterization and application of dibutyrate bis (2-hydroxyethyl) terephthalamide as a plasticizer in PVC compounding. Polymer Bulletin, 71(10): 2695-2707. https://doi.org/10.1007/s00289-0141218-y

[25] Park, S.H., Kim, S.H. (2014). Poly (ethylene terephthalate) recycling for high value added textiles. Fashion and Textiles, 1(1): 1-17. https://doi.org/10.1186/s40691-014-0001-x

[26] Khoonkari, M., Haghighi, A.H., Sefidbakht, Y., 
Shekoohi, K., Ghaderian, A. (2015). Chemical recycling of PET wastes with different catalysts. International Journal of Polymer Science, 2015: 124524. https://doi.org/10.1155/2015/124524

[27] Shehap, H.M., Alzuhairi, M.A., Ibrahim, S.I., Hussien, S.F. (2021). Recycling of wood - plastic composite prepared from poly (ethylene terephthalate) and wood sawdust. Engineering and Technology Journal, 39(11): 1654-1662. http://dx.doi.org/10.30684/etj.v39i11.2203

[28] Abas, F.O., Abass, R.U., Enas, A.A. (2014). The use of new techniques in the management of waste plastic by reuse it in the asphalt mix. Journal of Engineering and Technology, 32(10): 2548-2567.

[29] Awaja, F., Pavel, D. (2005). Recycling of PET. European Polymer Journal, 41(7): 1453-1477. https://doi.org/10.1016/j.eurpolymj.2005.02.005

[30] Kint, D., Muñoz-Guerra, S. (1999). A review on the potential biodegradability of poly (ethylene terephthalate). Polymer International, 48(5): 346-352. https://doi.org/10.1002/(SICI)10970126(199905)48:5\%3C346::AID-PI156\%3E3.0.CO;2$\mathrm{N}$ 